\title{
Evaluation of copper-dependent proteasome-inhibitory and apoptosis-inducing activities of novel pyrrolidine dithiocarbamate analogues
}

\author{
ZHIYONG YU ${ }^{1,4}$, FEI WANG ${ }^{2}$, VESNA MILACIC ${ }^{1}$, XIAOFENG LI $^{2}$, \\ QIUZHI CINDY CUI ${ }^{1}$, BIN ZHANG $^{2}$, BING YAN $^{2,3}$ and Q. PING DOU ${ }^{1}$
}

\author{
${ }^{1}$ The Prevention Program, Barbara Ann Karmanos Cancer Institute, Department of Pathology, \\ School of Medicine, Wayne State University, Detroit, MI, USA; ${ }^{2}$ School of Pharmaceutical Sciences, \\ Shandong University, Jinan, Shandong, P.R. China; ${ }^{3}$ Department of Chemical Biology and Therapeutics, \\ St. Jude Children's Research Hospital, Memphis, TN, USA; ${ }^{4}$ Breast Cancer Center, \\ Shandong Tumor Hospital and Institute, Jinan, Shandong, P.R. China
}

Received August 20,2007; Accepted September 26, 2007

\begin{abstract}
Apoptosis has a central role in the pathogenesis of many human diseases, one of which is cancer. One of the most important strategies to regulate apoptosis is via the ubiquitin-proteasome pathway. It has been shown that inhibition of proteasomal chymotrypsin-like activity is a strong apoptosis-inducing stimulus and that actively proliferating cancer cells are more sensitive to proteasome inhibitors than normal or untransformed cells. Dithiocarbamates are a class of metal-chelating compounds with various applications in medicine. We reported previously that certain members of dithiocarbamates, such as pyrrolidine dithiocarbamate (PDTC), diethyldithiocarbamate and disulfiram, are able to bind with tumor cellular copper, forming an active complex with proteasome-inhibitory, apoptosis-inducing and anti-cancer activities. In the current study, we synthesized eight PDTC analogues with substitutions made to the pyrrolidine ring and studied their structureactivity relationships. We found that substitution of the pyrrolidine ring with piperidine had almost no effect on their proteasome-inhibitory and anti-proliferative potencies in human breast cancer cells. However, after the pyrrolidine ring was substituted with morpholine, the activity of the
\end{abstract}

Correspondence to: Dr Q. Ping Dou, The Prevention Program, Barbara Ann Karmanos Cancer Institute, Department of Pathology, School of Medicine, Wayne State University, 540.1 HWCRC, 4100 John R Road, Detroit, MI 48201-2013, USA

E-mail: doup@karmanos.org

Dr Bing Yan, Department of Chemical Biology and Therapeutics, St. Jude Children's Research Hospital, 332 North Lauderdale Street, Memphis, TN 38105, USA

E-mail: bing.yan@stjude.org

Key words: pyrrolidine dithiocarbamate, proteasome inhibitors, apoptosis, cancer, drug discovery mixtures slightly decreased but was completely lost when piperazine with the attached ethyl group was used for the substitution. This structure-activity relationship was confirmed by the results generated with the corresponding copper complexes. Our data further support the novel concept of using accumulated copper in human cancer cells as a selective approach for chemotherapy.

\section{Introduction}

Apoptosis is an evolutionarily conserved cellular suicide program in multicellular organisms (1). It removes unwanted cells and thereby plays an essential role in development, tissue homeostasis, and defense against viral infections and mutations. In many human diseases, the genes controlling the apoptotic process are suppressed, overexpressed or altered by mutations (2). In disease states such as cancer, insufficient cell death is a common problem (3).

The ubiquitin-proteasome pathway is essential for many fundamental cellular processes, including the cell cycle, apoptosis, angiogenesis and differentiation (4). This pathway contributes to the pathological state of several human diseases including cancer, in which some regulatory proteins are either stabilized due to decreased degradation or lost due to accelerated degradation (5). The $20 \mathrm{~S}$ proteasome, the proteolytic core of the $26 \mathrm{~S}$ proteasome complex, contains multiple peptidase activities including the chymotrypsinlike/CT-like, trypsin-like and peptidylglutamyl peptide hydrolyzing-like/PGPH-like (6). It has been shown that inhibition of CT-like but not the other proteasomal activities is a strong stimulus that induces apoptosis $(7,8)$.

The ease of synthesis and structural manipulation of small molecules with apoptosis-inducing ability makes them attractive potential anti-cancer drugs. One group of small molecules with the potential to treat cancer is proteasome inhibitors. These inhibitors can block proteasome function without, or by slightly affecting, other normal biological processes in the cell. The fact that cancer cells are more 
sensitive to the proteasome inhibitors than normal or untransformed cells makes these small molecules even more attractive potential anti-cancer drugs (9-11).

Dithiocarbamates are a class of metal-chelating compounds with various applications in medicine for the treatment of bacterial and fungal infections, and the possible treatment of AIDS $(12,13)$. One of the dithiocarbamates, pyrrolidine dithiocarbamate (PDTC), is a synthetic antioxidant that has the potential to inhibit NFKB activation $(12,14)$. We previously found that PDTC forms a complex with copper and that this PDTC-copper complex inhibits proliferation and induces apoptosis in cultured breast and prostate cancer cells, triggered by the inhibition of the ubiquitin-proteasome pathway $(15,16)$.

In this study, we screened several PDTC analogues with substitutions made to the pyrrolidine ring for their structureactivity relationships. After we determined the effect of their copper complexes, we found that substitution of the pyrrolidine ring with piperidine had almost no effect on their proteasomeinhibitory potencies in human breast cancer cells. However, after the pyrrolidine ring was substituted with morpholine, the activity of the complexes slightly decreased but was completely lost when piperazine with the attached ethyl group was used for the substitution.

\section{Materials and methods}

Materials. Pyrrolidine dithiocarbamate (PDTC), $\mathrm{CuCl}_{2}$, disulfiram (DSF), 3-[4,5-dimethyltiazol-2-yl]-2.5-diphenyltetrazolium bromide (MTT), dimethylsulfoxide (DMSO) and additional chemicals were purchased from Sigma-Aldrich (St. Louis, MO, USA). DMEM/F12, fetal bovine serum, penicillin, and streptomycin were purchased from Invitrogen (Carlsbad, CA). Purified rabbit 20S proteasome, and fluorogenic peptide substrate Suc-LLVY-AMC for the proteasomal CT-like activity were from Calbiochem (San Diego, CA, USA). Mouse monoclonal antibody against human poly(ADP-ribose) polymerase (PARP) was purchased from Biomol International LP (Plymouth Meeting, PA). Mouse monoclonal antibodies against Bax (B-9), p27 (F-8), and ubiquitin (P4D1), goat polyclonal antibody against actin (C-11), rabbit polyclonal antibody against IкB- $\alpha$ (C-15), and secondary antibodies were from Santa Cruz Biotechnology, Inc. (Santa Cruz, CA). All the chemicals used for synthesis of PDTC analogues were purchased from Acros. The water used in this study was purified by reverse osmosis on a MilliRo followed by ion exchange (Cascada, USA). The copper solution was prepared by dissolving $\mathrm{CuCl}_{2}$ in the purified water. All the fluorescence intensity was measured by the F-4500 spectrofluorimeter (Hitachi, Japan). Compound identifications were confirmed by Proton Nuclear Magnetic Resonance (NMR) AVANCE 400 (Bruker, Germany).

Synthesis of PDTC analogues. Dialkyl-substituted dithiocarbamate analogues were prepared by the one-step reaction of secondary amine with carbon bisulfide in sodium hydroxide and methanol (17) (scheme, top, right). The mixture was heated to $40^{\circ} \mathrm{C}$ and stirred well for $30-120 \mathrm{~min}$, and the methanol was then removed by distillation. Crude products were further purified by recrystallization.

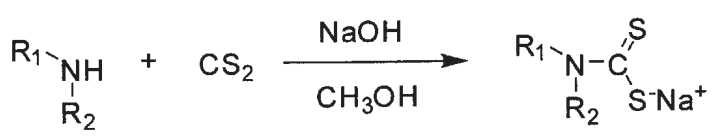

Measurement of binding constants of PDTC analogues and $\mathrm{Cu}^{2+}$. The binding constant between a PDTC analogue and $\mathrm{Cu}^{2+}$ was determined by fluorescence spectroscopy at $25^{\circ} \mathrm{C}$. The concentration of the PDTC analogue solution was $100 \mu \mathrm{M}$ and the concentration of the $\mathrm{Cu}^{2+}$ was increased stepwise from 5 to $250 \mu \mathrm{M}$.

Cell culture and cell extract preparation. MDA-MB-231 cells were grown in DMEM/F12 supplemented with $10 \%$ fetal bovine serum, 100 units $/ \mathrm{ml}$ of penicillin, and $100 \mu \mathrm{g} / \mathrm{ml}$ of streptomycin, at $37^{\circ} \mathrm{C}$ in a humidified incubator with an atmosphere of $5 \% \mathrm{CO}_{2}$. A whole cell extract was prepared as previously described (7).

Proteasome activity assay. MDA-MB-231 breast cancer cells were grown to $70-80 \%$ confluency, treated under various conditions, harvested, and then used for whole cell extract preparation. Cell extract $(10 \mu \mathrm{g})$ was used to determine the proteasomal chymotrypsin-like activity, as previously described (16).

Cell proliferation assay. The MTT assay was used to determine the effects of the various compounds on breast cancer cell proliferation. Cells were plated in a 96-well plate and grown to $70-80 \%$ confluency, followed by the addition of each PDTC-Cu complex at the indicated concentrations. After a $24-\mathrm{h}$ incubation at $37^{\circ} \mathrm{C}$, inhibition of cell proliferation was measured as previously described (18).

Cellular morphology analysis. A Zeiss (Thornwood, NY) Axiovert 25 microscope with phase contrast was used for cellular morphology, as previously described (15).

Western blot analysis. MDA-MB-231 cells were treated, harvested and lysed. Cell lysates $(50 \mu \mathrm{g})$ were separated by SDS-PAGE and transferred to a nitrocellulose membrane, followed by visualization using the enhanced chemiluminescence kit (Amersham Biosciences, Piscataway, NJ), as previously described (16).

\section{Results}

Synthesis and characterization of PDTC analogues. Eight secondary amines and pyrrolidine as a control were used for the synthesis of PDTC analogues and PDTC, respectively (Fig. 1A). Since these compounds have different nucleophilicity, the reactions were carried out under different conditions. Amines such as piperidine and morpholine are easily able to react with $\mathrm{CS}_{2}$ in $\mathrm{NaOH}$ at room temperature with a high yield of $90 \%$. Secondary amines containing aromatic groups are less reactive and were treated at higher temperature $\left(50^{\circ} \mathrm{C}\right)$ and yielded $\sim 50 \%$ of final product.

Mixtures of PDTC analogues with copper inhibit MDA-MB231 cell proliferation. We previously demonstrated that a mixture of PDTC and copper selectively inhibits proliferation 
A
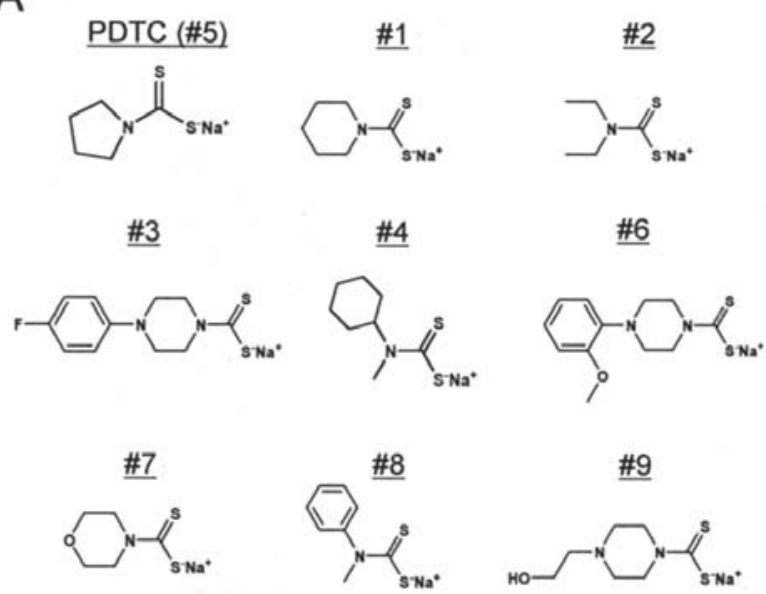

B

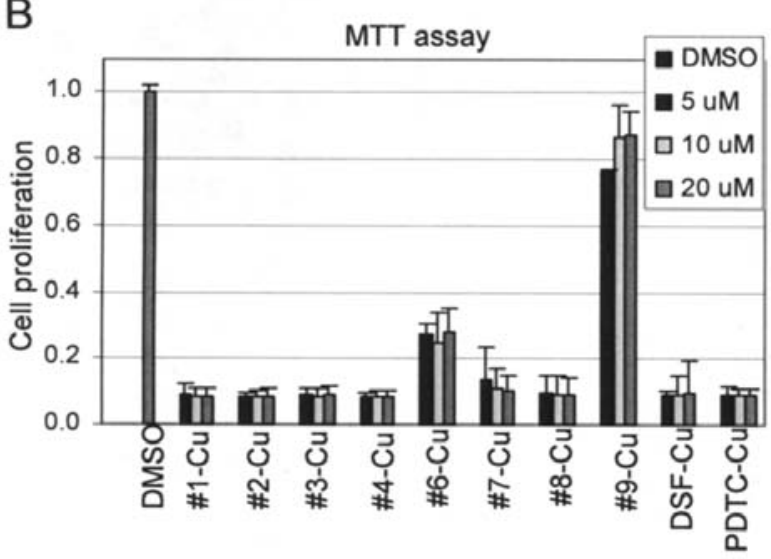

Figure 1. (A) Chemical structures of PDTC and eight PDTC analogues. (B) Anti-proliferative effect of the copper mixtures with different PDTC analogues. MDA-MB-231 cells were treated for $24 \mathrm{~h}$ with different concentrations of the mixtures, as indicated. After $24 \mathrm{~h}$, the medium was removed, and the cells were treated with MTT solution as described in Materials and methods. DMSO was used as a control.

and induces apoptosis in malignant and pre-malignant but not in normal breast cancer cells (15). To investigate the antiproliferative potency of eight newly synthesized PDTC analogues (Fig. 1A), we mixed each of them with a solution of copper chloride at a 1:1 ratio ( $\mathrm{vol}: \mathrm{vol})$. Highly metastatic MDA-MB-231 breast cancer cells were then treated with 5, 10 and $20 \mu \mathrm{M}$ concentrations of each of all eight mixtures for $24 \mathrm{~h}$, followed by MTT assay. In this experiment, PDTC-Cu and DSF-Cu were used as positive controls $(15,19)$. We found that the copper-containing mixtures of PDTC analogues $\# 1, \# 2, \# 3, \# 4$ and \#8 had similar growth-inhibitory potency to that of PDTC-Cu and DSF-Cu, causing 90\% inhibition at $5 \mu \mathrm{M}$ (Fig. 1B). Analogue \#7-Cu was slightly less potent (Fig. 1B) and the analogue \#6-Cu mixture at 5-20 $\mu \mathrm{M}$ inhibited only $\sim 70 \%$ of MDA-MB-231 cell proliferation (Fig. 1B). The least potent of all tested PDTC analogues was analogue \#9, since its mixture with copper inhibited only $\sim 20 \%$ of cell growth even at the highest concentration used $(20 \mu \mathrm{M})$ (Fig. 1B). Therefore, the copper-based growthinhibitory potential of PDTC analogues is related to their chemical structures.
Mixtures of PDTC analogues with copper inhibit cellular proteasome activity and induce apoptosis in a dosedependent manner. To further study the structure-activity relationships, we chose the three most related PDTC analogues, \#1, \#7 and \#9. After we mixed analogues \#1, \#7 or \#9 with copper(II) chloride, color changes, indicative of complex formation, were observed (Fig. 2A). The most intensive color change was observed with the analogue \#1 mixture with copper (\#1-Cu).

We first performed a dose-dependent experiment. Breast cancer MDA-MB-231 cells were treated with each mixture at concentrations of $0.5,2.5$, and $5 \mu \mathrm{M}$ for $16 \mathrm{~h}$, followed by measurement of proteasome inhibition and apoptotic cell death by multiple assays. All the PDTC analogue-copper mixtures inhibited the proteasomal CT-like activity in a dosedependent manner (Fig. 2B). Consistent with their antiproliferative activities (Fig. 1B), the copper mixture of analogue \#1 was found to be the most potent, by inducing $\sim 90 \%$ of proteasomal inhibition at the highest concentration used (Fig. 2B). Analogue \#7 mixed with copper had a lightly weaker effect; it induced $\sim 83 \%$ inhibition at the highest concentration. In contrast, analogue \#9 mixed with copper was found to be the least potent; it inhibited only $30 \%$ of the proteasomal activity at the highest concentration (Fig. 2B). Additionally, a dose-dependent accumulation of ubiquitinated proteins and a ubiquitinated form (indicated by an arrow, Fig. 2C) of the natural proteasome target IкB- $\alpha$ (20) was detected by Western blot analysis only in the cells treated with \#1-Cu and \#7-Cu mixtures.

We and others have shown that, associated with the apoptotic commitment, Bax protein (p21/Bax) is cleaved by calpain, producing a $\mathrm{p} 18 / \mathrm{Bax}$ fragment, which then forms a homodimer p36/Bax $(21,22)$. We observed the accumulation of p36/Bax protein mainly in the cells treated with \#1-Cu and \#7-Cu mixtures (Fig. 2C), suggesting calpain involvement.

In the same experiment, morphological changes (shrunken cells and characteristic apoptotic blebbing) were detected in the cells treated with 2.5 and $5.0 \mu \mathrm{M}$ of \#1-Cu mixture and $5.0 \mu \mathrm{M}$ of \#7-Cu mixture, but not \#9-Cu mixture even at the highest concentration used (Fig. 2D). A dose-dependent production of cell death-specific PARP cleavage fragment p65 was detected in MDA-MB-231 cells treated only with \#1-Cu and \#7-Cu mixtures (Fig. 2C). This further supports calpain activation since it has been shown that calpain cleaves PARP into a fragment of $\sim 65 \mathrm{kDa}$ (23). Our results demonstrated that the rank of the cell death-inducing activities of these PDTC analogues is the same as that of their proteasome-inhibitory potentials, which is \#1 $>\# 7>>\# 9$.

Time-dependent proteasome inhibition and apoptosis induction by \#1-Cu mixture. We showed that among the three tested PDTC analogues, the mixture of \#1 with copper(II) chloride was the most potent proteasome inhibitor and apoptosis inducer in intact MDA-MB-231 cells. To ascertain whether proteasome inhibition is the causative factor or the consequence of apoptosis, we performed a kinetic experiment. MDA-MB-231 cells were treated with a $5 \mu \mathrm{mol} / \mathrm{l}$ mixture of $\# 1$ and copper for up to $16 \mathrm{~h}$. We found $25 \%$ inhibition of the proteasomal CT-like activity by the \#1-Cu mixture after $0.5 \mathrm{~h}$ of treatment, $\sim 40 \%$ inhibition after $4 \mathrm{~h}$, and $\sim 70 \%$ 
A

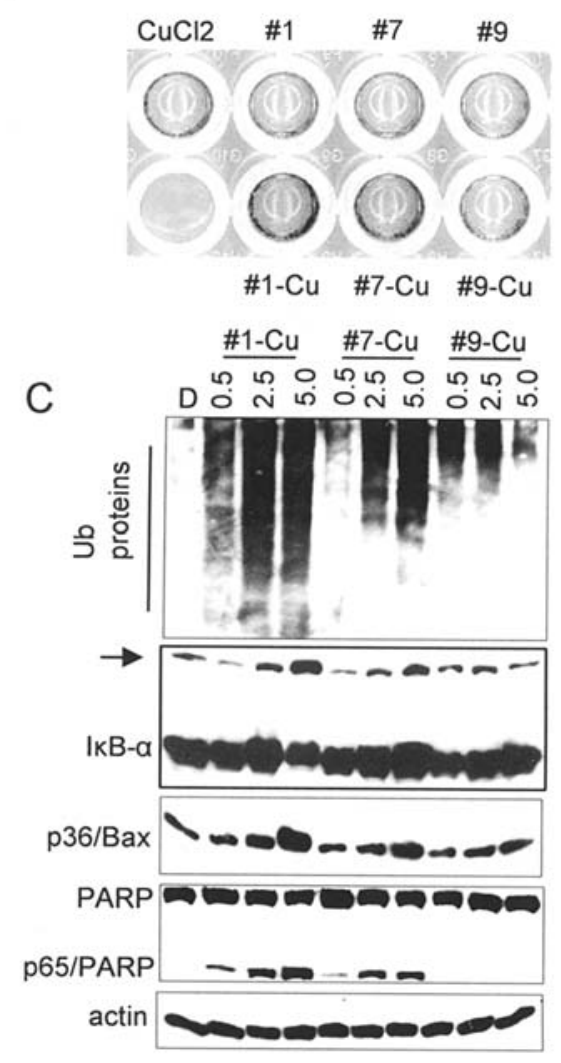

B
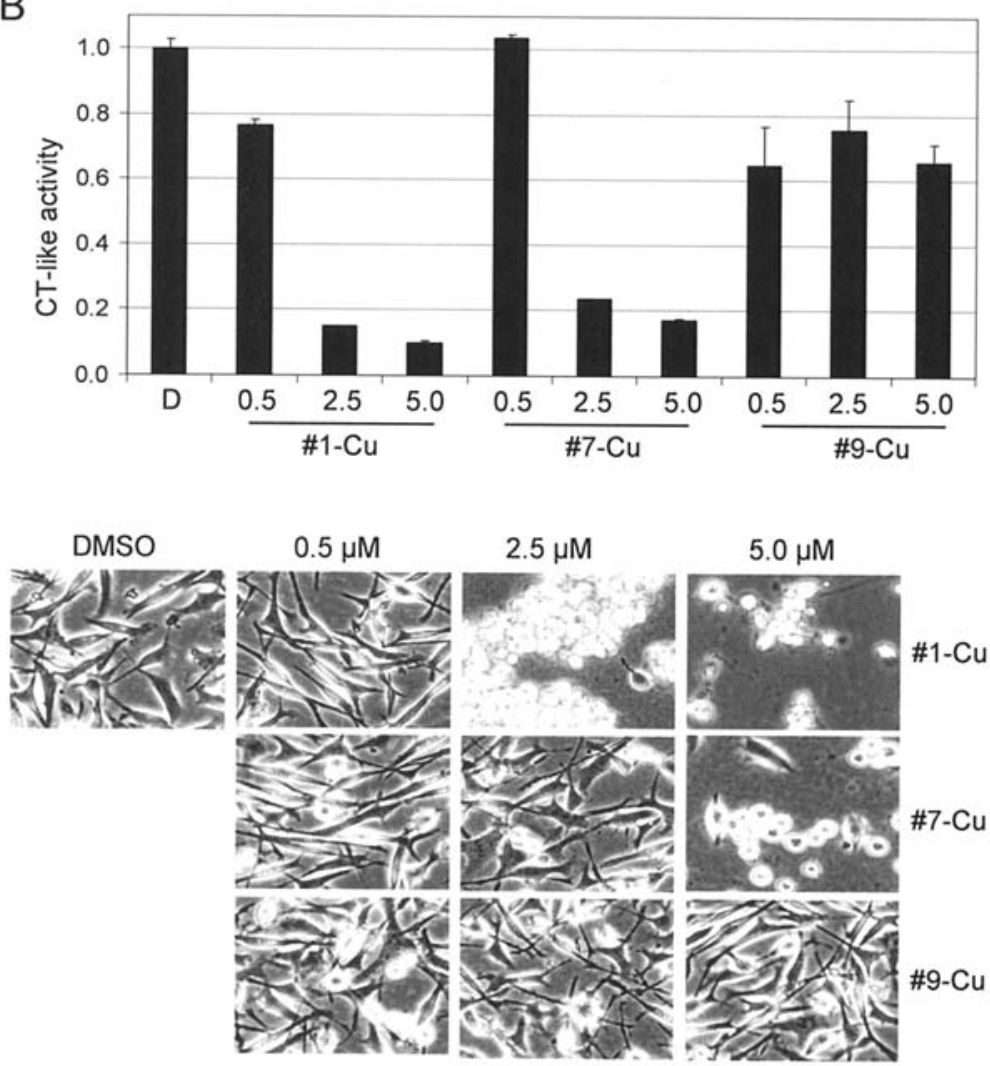

Figure 2. Proteasomal inhibition and apoptosis induction by copper mixtures with PDTC analogues. (A) Copper complex formation is indicated by color change. PDTC analogues \#1, \#7 and \#9 (20 mM) were mixed in a 1:1 molar ratio with $\mathrm{CuCl}_{2}$. All solutions were made in DMSO. (B) The cells were treated with concentrations of $0.5,2.5$ and $5 \mu \mathrm{M}$ of the indicated mixtures for $24 \mathrm{~h}$, followed by the measurement of proteasomal CT-like activity. (C) Western blot analysis for the accumulation of ubiquitinated proteins, proteasome target proteins IкB- $\alpha$ and p36/Bax, and PARP cleavage in the extracts prepared from the cells treated for $24 \mathrm{~h}$. The arrow indicates the ubiquitinated form of IкB- $\alpha$. (D) Apoptotic morphological changes in the MDA-MB-231 cells treated for $24 \mathrm{~h}$ as indicated, visualized by phase-contrast imaging.

inhibition after $10 \mathrm{~h}$ (Fig. 3A). Proteasome inhibition was confirmed by the accumulation of ubiquitinated proteins and the ubiquitinated IкB- $\alpha$ (Fig. 3B). Apoptotic morphological changes were observed after $4 \mathrm{~h}$ of treatment (Fig. 3C), and cell death-related, calpain-mediated PARP cleavage fragment p65 appeared after $10 \mathrm{~h}$ of treatment (Fig. 3B). Consistent with calpain activation, levels of p36/Bax homodimer were increased at $\sim 10 \mathrm{~h}$ (Fig. 3B). These data suggest that the PDTC analogue \#1-Cu mixture causes proteasome inhibition at an early time point, followed by calpain activation and apoptosis induction.

Effect of synthetic PDTC analogue-copper complexes. To confirm the results generated with the mixtures of the PDTC analogues and copper (Figs. 1-3), we synthesized complexes \#1-Cu, \#7-Cu and \#9-Cu, each with the PDTC analogue:copper molar ratio 2:1. After MDA-MB-231 cells were treated with each synthetic complex at a $10 \mu \mathrm{M}$ concentration for $24 \mathrm{~h}$ (Fig. 4A), we again found that complex \#1 induced more apoptotic morphological changes than complex \#7, while complex \#9 did not induce any morphological changes (Fig. 4A), consistent with the results obtained from the three mixtures (see Fig. 2D).

Failure of complex \#9 to inhibit the proteasome and to induce cell death could have been due to the fact that i) analogue \#9 is a poor copper-binding ligand and/or ii) complex \#9 is an inactive compound. To distinguish between these two possibilities, we investigated the binding affinity of analogue \#9 to copper, using analogues \#1 and \#7 as controls. The binding constant of analogue \#9 to $\mathrm{Cu}^{2+}$ $\left(2.3 \times 10^{4}\right)$ was similar to that of analogue \#7 to $\mathrm{Cu}^{2+}$ $\left(2.6 \times 10^{4}\right)$, and weaker than analogue $\# 1$ to $\mathrm{Cu}^{2+}\left(8.5 \times 10^{4}\right)$. We also found that after the addition of $\mathrm{Cu}^{2+}$, the fluorescence intensity of analogues \#1 and \#7, as well as all other ligands (data not shown), increased while the fluorescent intensity of \#9 was quenched (Fig. 4B), indicating that the binding mode between $\mathrm{Cu}^{2+}$ and $\# 9$ was different from $\mathrm{Cu}^{2+}$ complexes with ligands \#1 through \#8. Since analogue \#9 had a binding affinity to copper similar to that of analogue \#7, but complex \#9 was much less potent than complexes \#1 and \#7 (Figs. 2 and 4A), we conclude that complex \#9 is a weak proteasome inhibitor and apoptosis inducer.

We then investigated the anti-proliferation potency of synthetic complex \#1 by an MTT assay and found that after $24 \mathrm{~h}$ of treatment, at a $1 \mu \mathrm{M}$ concentration it inhibited $\sim 80 \%$ of MDA-MB-231 cell proliferation and at $20 \mu \mathrm{M}$ caused $\sim 90 \%$ inhibition (Fig. 4C). Then, we treated MDA-MB-231 cells with $10 \mu \mathrm{mol} / \mathrm{l}$ of synthetic complex \#1-Cu up to $24 \mathrm{~h}$, followed by the measurement of the proteasomal inhibition. We found that $\sim 40 \%$ of the proteasomal CT-like activity 
A

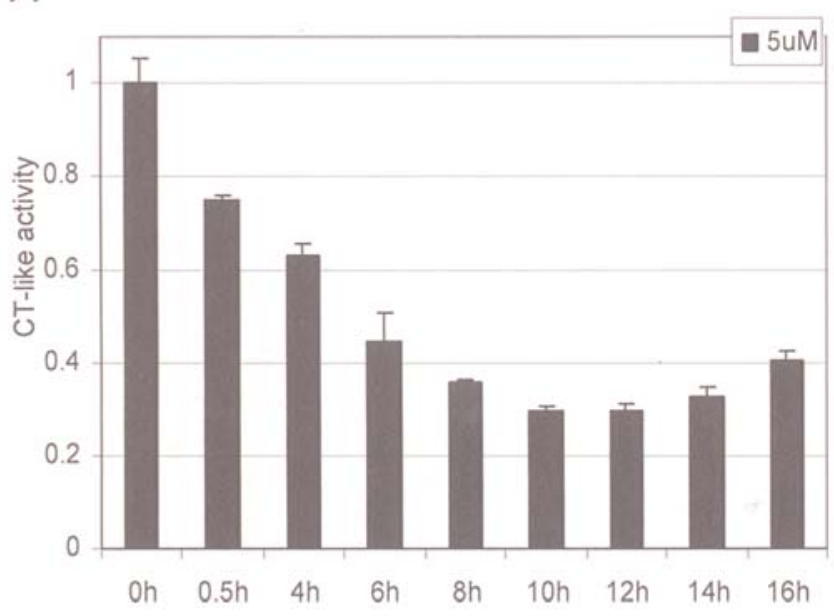

B

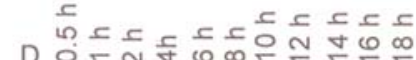

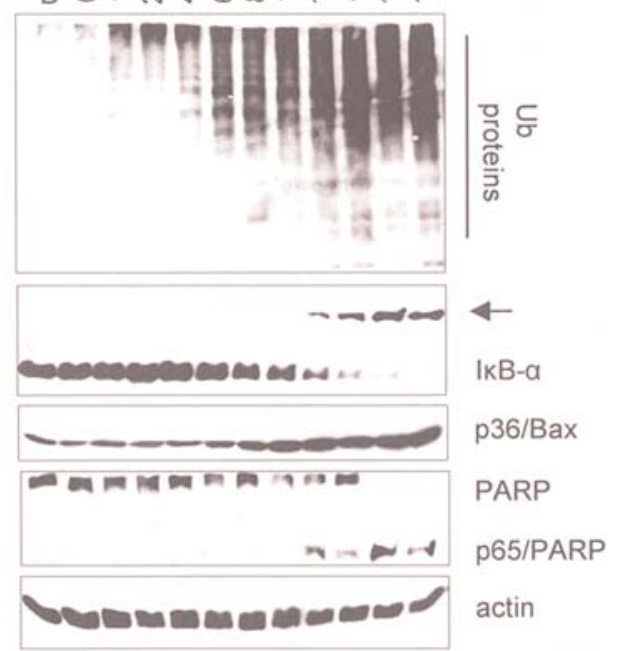

$2 \mathrm{~h}$

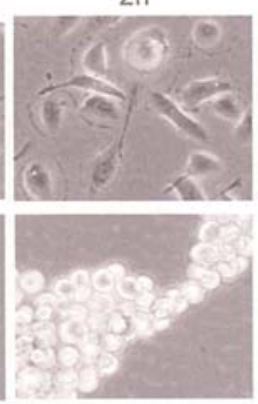

$12 \mathrm{~h}$ 4h

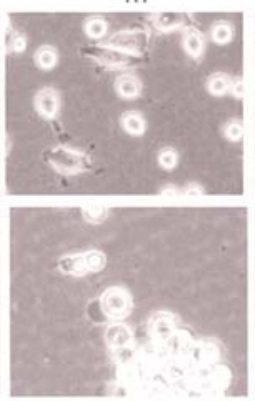

$14 \mathrm{~h}$
$6 h$

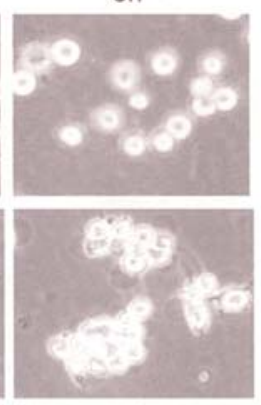

$16 \mathrm{~h}$

Figure 3. Kinetic studies of the proteasome inhibition and apoptosis induction by \#1-Cu mixture in MDA-MB-231 cells. MDA-MB-231 cells were exposed to a $5 \mu \mathrm{M}$ mixture of PDTC analogue \#1 and copper for the indicated times, followed by measurement of the proteasomal CT-like activity (A), and Western blot analysis using specific antibodies to ubiquitin, IкB- $\alpha$, Bax, PARP, and B-actin. Arrow indicates the ubiquitinated form of IкB- $\alpha$ (B). Apoptotic morphological changes of MDA-MB-231 cells treated with a $5 \mu \mathrm{M}$ mixture of PDTC analogue \#1 and copper for the indicated times (C).

was inhibited at the early and late time points (Fig. 4D). Proteasomal inhibition was confirmed by Western blot analysis which showed accumulation of the ubiquitinated form of proteasome target protein IкB- $\alpha$ (Fig. 4E). In the same kinetic experiment, apoptotic morphological changes (shrunken cells and characteristic apoptotic blebbing) were detected mostly after $24 \mathrm{~h}$ of treatment (data not shown). Therefore, we conclude that PDTC analogue \#1, a piperidine dithiocarbamate, is a copper-based proteasome inhibitor and a cancer cell apoptosis inducer.

\section{Discussion}

The ubiquitin-proteasome pathway plays a major role in the degradation of proteins involved in cell cycle progression, proliferation, and apoptosis. This pathway was also shown to play a critical role in cancer cells and is a novel target for inhibiting tumor progression and overcoming drug resistance (24). Moreover, proteasome inhibitors are potent apoptosis inducers and cancer cells are more sensitive to proteasome inhibition compared to normal cells (7,9-11). However, because of the vital nature of the proteasome, the possibility of targeting it therapeutically was met with great skepticism.
With the first demonstration that proteasome inhibitors were well tolerated and active in models of human malignancies in vivo (25), they were introduced into Phase I safety trials. Bortezomib was the first proteasome inhibitor to receive regulatory approval from the US Food and Drug Administration for the treatment of multiple myeloma (26). However, the main drawback of bortezomib is the overall toxicity that very often causes an early cessation of the treatment. In the search for new, more potent and less toxic, proteasome inhibitors, we previously showed that PDTC forms a complex with copper that inhibits the proteasomal activity and cell proliferation, and induces apoptosis in breast and prostate cancer cells, but not in normal cells $(15,16)$.

In this study, we characterized a structure-activity relationship between different substitution groups on the pyrrolidine ring of PDTC. We determined that the size and polarity of the ring within PDTC was important for them to complex with copper by measuring the color change (Fig. 2A) and binding constants (Fig. 4C). We also measured the antiproliferative activity of the complexes by the MTT assay. After the pyrrolidine ring was substituted with the more polar and larger groups, in analogues \#6 and \#9, the potency of their mixtures with copper to inhibit the proliferation of 
A

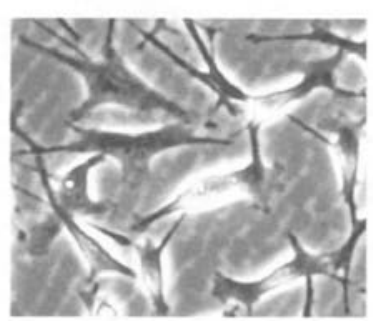

DMSO

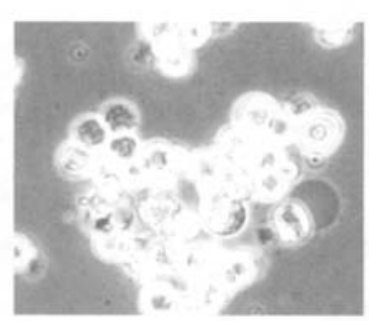

Complex \#1

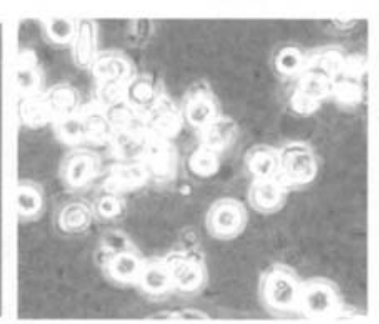

Complex \#7

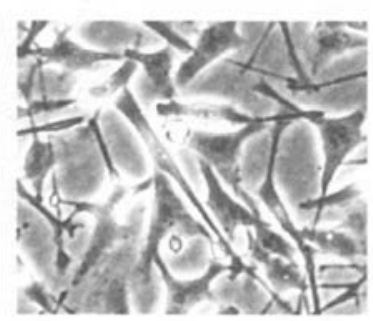

Complex \#9

B

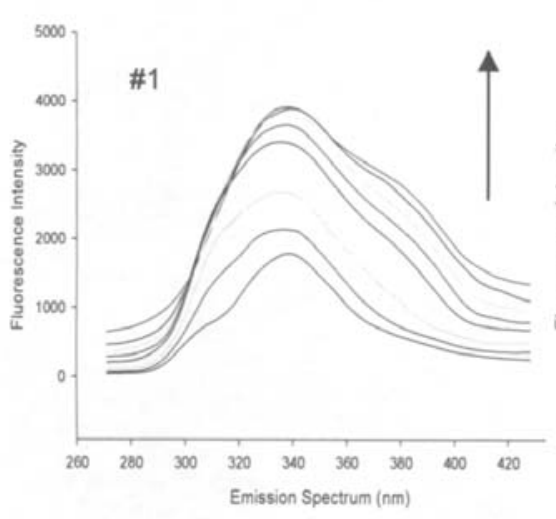

C

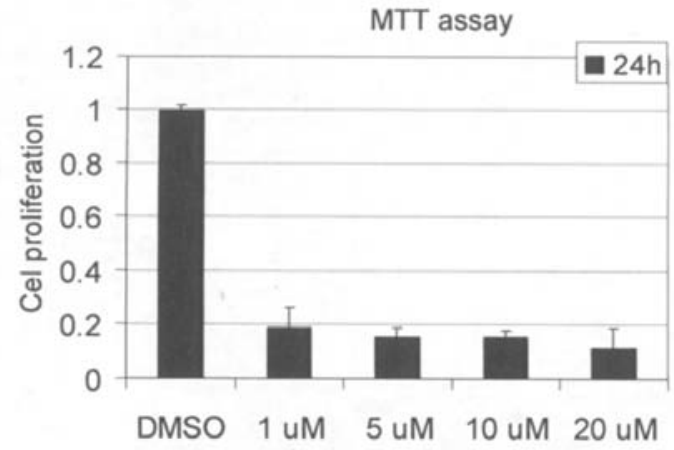

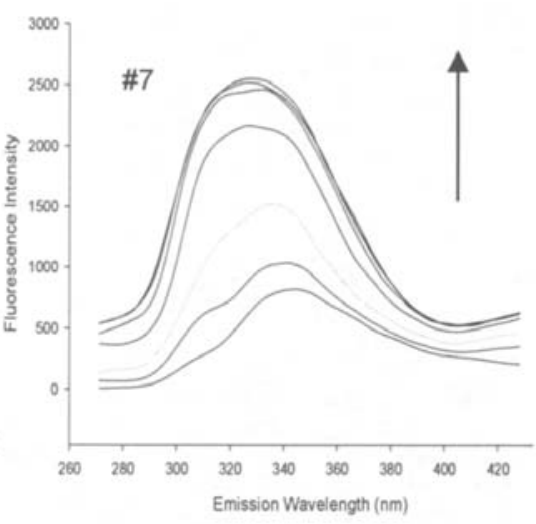

D

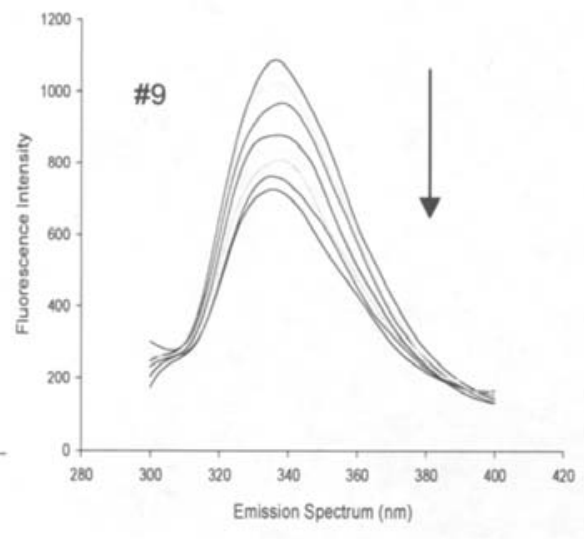

E

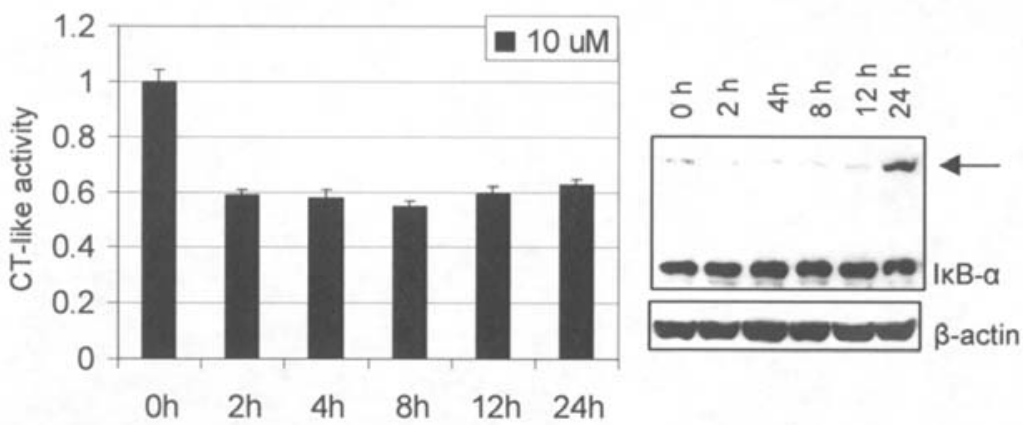

Figure 4. Synthetic \#1-Cu compound inhibits MDA-MB-231 cell proliferation and the proteasomal CT-like activity in intact MDA-MB-231 cells. (A) Apoptotic morphological changes in MDA-MB-231 cells treated for $24 \mathrm{~h}$ with synthetic complexes \#1-Cu, \#7-Cu, and \#9-Cu. (B) Fluorescence spectra of PDTC analogues \#1, \#7, and \#9 binding with copper. (C) Anti-proliferative effect of synthetic complex \#1-Cu was measured by MTT assay. MDA-MB-231 cells were treated for $24 \mathrm{~h}$ with different concentrations of the complex \#1-Cu, followed by the treatment with MTT solution, as described in Materials and methods. DMSO was used as a control. (D) MDA-MB-231 cells were treated with $10 \mu \mathrm{M}$ synthetic \#1-Cu complex as indicated. Cell extract (10 $\mu \mathrm{g}$ per reaction) was then incubated for $2 \mathrm{~h}$ with a peptide substrate for the proteasomal CT-like activity. (E) Western blot analysis using specific antibodies to IKB- $\alpha$. Actin was used as a loading control.

breast cancer cells significantly decreased. We also showed that pyrrolidine substitution with piperidine (analogue \#1) had almost no effect on the proteasome-inhibitory and cell death-inducing activities of the mixture or complex. However, pyrrolidine substitution with morpholine (analogue \#7) slightly decreased the activity of the mixture, which was then completely lost when piperazine with the attached hydroxyethyl group was used for the substitution (analogue \#9).

In conclusion, these data support the novel concept of using accumulated copper in human cancer cells as a selective approach for chemotherapy. The nontoxic copper-binding ligands such as PDTC analogue \#1 are able to spontaneously bind with tumor cellular copper and form a proteasome inhibitor and an apoptosis inducer. Our study strongly suggests that cancer cells and tissues, which contain elevated copper and are more dependent on proteasome activity for their survival, should be very sensitive to such a treatment.

\section{Acknowledgements}

This study was supported by a grant from the Karmanos Cancer Institute of Wayne State University (to Q.P. Dou), the Department of Defense Breast Cancer Research Program Awards (W81XWH-04-1-0688 and DAMD17-03-1-0175 to Q.P. Dou), and the NCI/NIH Cancer Center Support Grant (to Karmanos Cancer Institute). We thank Dr Di Chen for his assistance and Ms Zhenwei Li for the technical assistance in the fluorescence spectroscopy measurements. 


\section{References}

1. Jacobson MD, Weil M and Raff MC: Programmed cell death in animal development. Cell 88: 347-354, 1997.

2. Thatte U and Dahanukar S: Apoptosis - clinical relevance and pharmacological manipulation. Drugs 54: 511-532, 1997.

3. Song $\mathrm{Z}$ and Steller H: Death by design: mechanism and control of apoptosis. Trends Cell Biol 9: M49-M52, 1999.

4. Orlowski RZ and Dees EC: Applying drugs that affect the ubiquitin-proteasome pathway to the therapy of breast cancer. Breast Cancer Res 5: 1-7, 2003.

5. Ciechanover A: The ubiquitin-proteasome pathway: on protein death and cell life. EMBO J 17: 7151-7160, 1998.

6. Seemuller E, Lupas A, Stock D, Lowe J, Huber R and Baumeister W: Proteasome from Thermoplasma acidophilum: a threonine protease. Science 268: 579-582, 1995.

7. An B, Goldfarb RH, Siman R and Dou QP: Novel dipeptidyl proteasome inhibitors overcome Bcl-2 protective function and selectively accumulate the cyclin-dependent kinase inhibitor p27 and induce apoptosis in transformed, but not normal, human fibroblasts. Cell Death Differ 5: 1062-1075, 1998.

8. Lopes UG, Erhardt P, Yao R and Cooper GM: p53-dependent induction of apoptosis by proteasome inhibitors. J Biol Chem 272: 12893-12896, 1997.

9. Adams J: Potential for proteasome inhibition in the treatment of cancer. Drug Discov Today 8: 307-315, 2003.

10. Almond JB and Cohen GM: The proteasome: a novel target for cancer chemotherapy. Leukemia 16: 433-443, 2002.

11. Dou QP and Li B: Proteasome inhibitors as potential novel anticancer agents Drug Resist Update 2: 215-223, 1999.

12. Schreck R, Meier B, Mannel DN, Droge W and Baeuerle PA: Dithiocarbamates as potent inhibitors of nuclear factor kappa B activation in intact cells. J Exp Med 175: 1181-1194, 1992.

13. Malaguarnera L, Pilastro MR, DiMarco R, Scifo C, Renis M, Mazzarino MC and Messina A: Cell death in human acute myelogenous leukemic cells induced by pyrrolidine dithiocarbamate. Apoptosis 8: 539-545, 2003.

14. Parodi FE, Mao D, Ennis TL, Bartoli MA and Thompson RW: Suppression of experimental abdominal aortic aneurysms in mice by treatment with pyrrolidine dithiocarbamate, an antioxidant inhibitor of nuclear factor-kappaB. J Vasc Surg 41: 479-489, 2005.

15. Daniel KG, Chen D, Orlu S, Cui QC, Miller FR and Dou QP: Clioquinol and pyrrolidine dithiocarbamate complex with copper to form proteasome inhibitors and apoptosis inducers in human breast cancer cells. Breast Cancer Res 7: R897-R908, 2005.
16. Chen D, Peng F, Cui QC, Daniel KG, Orlu S, Liu J and Dou QP Inhibition of prostate cancer cellular proteasome activity by a pyrrolidine dithiocarbamate-copper complex is associated with suppression of proliferation and induction of apoptosis. Front Biosci 10: 2932-2939, 2005.

17. Clifford AM and Lichty JG: Esters of dithiocarbamic acids. J Am Chem Soc 54: 1163-1166, 1932.

18. Milacic V, Chen D, Ronconi L, Landis-Piwowar KR, Fregona D and Dou QP: A novel anticancer gold(III) dithiocarbamate compound inhibits the activity of a purified $20 \mathrm{~S}$ proteasome and $26 \mathrm{~S}$ proteasome in human breast cancer cell cultures and xenografts. Cancer Res 66: 10478-10486, 2006

19. Chen D, Cui QC, Yang H and Dou QP: Disulfiram, a clinically used anti-alcoholism drug and copper-binding agent, induces apoptotic cell death in breast cancer cultures and xenografts via inhibition of the proteasome activity. Cancer Res 66: 10425-10433, 2006.

20. Chen D, Daniel KG, Chen MS, Kuhn DJ, Landis-Piwowar KR and Dou QP: Dietary flavonoids as proteasome inhibitors and apoptosis inducers in human leukemia cells. Biochem Pharmacol 69: 1421-1432, 2005.

21. Gao G and Dou QP: N-terminal cleavage of Bax by calpain generates a potent proapoptotic $18-\mathrm{kDa}$ fragment that promotes $\mathrm{Bcl}-2$-independent cytochrome $\mathrm{C}$ release and apoptotic cell death. J Cell Biochem 80: 53-72, 2000.

22. Wood DE and Newcomb EW: Cleavage of Bax enhances its cell death function. Exp Cell Res 256: 375-382, 2000.

23. Pink JJ, Wuerzberger-Davis S, Tagliarino C, Planchon SM, Yang X, Froelich CJ and Boothman DA: Activation of a cysteine protease in MCF-7 and T47D breast cancer cells during B-Lapachone-mediated apoptosis. Exp Cell Res 255: 144-155, 2000.

24. Landis-Piwowar KR, Milacic V, Chen D, Yang H, Zhao Y, Chan TH, Yan B and Dou QP: The proteasome as a potential target for novel anticancer drugs and chemosensitizers. Drug Resist Update 9: 263-273, 2006.

25. Orlowski RZ, Eswara JR, Lafond-Walker A, Grever MR, Orlowski $\mathrm{M}$ and Dang CV: Tumor growth inhibition induced in a murine model of human Burkitt's lymphoma by a proteasome inhibitor. Cancer Res 58: 4342-4348, 1998.

26. Canfield SE, Zhu K, Williams SA and McConkey DJ: Bortezomib inhibits docetaxel-induced apoptosis via a p21dependent mechanism in human prostate cancer cells. Mol Cancer Ther 5: 2043-2050, 2006. 